\title{
Educational needs of health care providers working in long-term care facilities with regard to pain management
}

\author{
Yannick Tousignant-Laflamme RPT PhD ${ }^{1,2}$, Michel Tousignant RPT PhD ${ }^{1,3}$, David Lussier MD MSc ${ }^{4,5}$, \\ Paule Lebel MD MSc ${ }^{6}$, Maryse Savoie RN MSc ${ }^{7}$, Lyne Lalonde BPharm PhD ${ }^{8,9,10}$, Manon Choinière PhD ${ }^{11,12}$
}

\begin{abstract}
Y Tousignant-Laflamme, M Tousignant, D Lussier, et al. Educational needs of health care providers working in long-term care facilities with regard to pain management. Pain Res Manage 2012;17(5):341-346.
\end{abstract}

BACKGROUND: The prevalence of chronic pain ranges from $40 \%$ to $80 \%$ in long-term care facilities (LTCF), with the highest proportion being found among older adults and residents with dementia. Unfortunately, pain in older adults is underdiagnosed, undertreated, inadequately treated or not treated at all. A solution to this problem would be to provide effective and innovative interdisciplinary continuing education to health care providers ( $\mathrm{HCPs}$ ).

OBJECTIVE: To identify the educational needs of HCPs working in LTCF with regard to pain management.

METHODS: A qualitative research design using the nominal group technique was undertaken. Seventy-two HCPs (21 physicians/pharmacists, 15 occupational/physical therapists, 24 nurses and 21 orderlies) were recruited from three LTCF in Quebec. Each participant was asked to provide and prioritize a list of the most important topics to be addressed within a continuing education program on chronic pain management in LTCF. RESULTS: Forty topics were generated across all groups, and six specific topics were common to at least three out of the four HCP groups. Educational need in pain assessment was ranked the highest by all groups. Other highly rated topics included pharmacological treatment of pain, pain neurophysiology, nonpharmacological treatments and how to distinguish pain expression from other behaviours.

CONCLUSION: The present study showed that despite an average of more than 10 years of work experience in LTCF, HCPs have significant educational needs in pain management, especially pain assessment. These results will help in the development of a comprehensive pain management educational program for HCPs in LTCF.

Key Words: Continuing education; Educational needs; Long-term care facilities; Nursing homes; Older persons; Pain management

$\mathrm{T}$ he prevalence of chronic pain among community-dwelling older adults is estimated to be between $27 \%$ and $57 \%(1-3)$ and has been reported to be even higher in those residing in long-term care facilities (LTCF) $(1,4,5)$. Although the exact percentage is difficult to determine given the difficulties in communication encountered with many residents, studies report point prevalence of pain ranging from $40 \%$ to $80 \%(6,7)$, with the highest proportion being found among very old residents with dementia (8-10).

Many factors may contribute to higher rates of chronic pain in older adults, including intrinsic factors related to aging. The prevalence and severity of several degenerative diseases associated with pain, such as osteoarthritis and other musculoskeletal pathologies, increase with age

\section{Les besoins de formation sur la prise en charge de la douleur de la part des dispensateurs de soins qui travaillent dans des établissements de longue durée}

HISTORIQUE : La prévalence de douleur chronique varie de $40 \%$ à $80 \%$ dans les établissements de soins de longue durée (ÉSLD), la proportion la plus élevée s'observant chez les adultes âgés et les résidents atteints de démence. Malheureusement, la douleur est sous-diagnostiquée, sous-traitée, traitée de manière inadéquate ou pas traitée du tout chez les adultes âgés. Une solution consisterait à prodiguer aux dispensateurs de soins (DdS) une formation interdisciplinaire continue efficace et novatrice.

OBJECTIF : Déterminer les besoins de formation des DdS qui travaillent dans des ÉSLD en matière de prise en charge de la douleur.

MÉTHODOLOGIE : Les chercheurs ont adopté une méthodologie de recherche qualitative faisant appel à la technique du groupe nominal. Ils ont recruté 72 DdS (21 médecins ou pharmaciens, 15 ergothérapeutes ou physiothérapeutes, 24 infirmières et 21 préposés aux bénéficiaires) dans trois ESLD du Québec. Ils ont invité chaque participant à fournir une liste des sujets les plus importants à aborder dans un programme de formation continue sur la prise en charge de la douleur chronique dans les ÉSLD, classée par ordre de priorité.

RÉSULTATS : Quarante sujets ont été suggérés par l'ensemble des groupes, et six sujets précis étaient communs à au moins trois des quatre groupes de DdS. Tous les groupes accordaient la priorité aux besoins de formation sur l'évaluation de la douleur. Parmi les autres sujets ayant obtenu une note élevée, soulignons le traitement pharmacologique de la douleur, la neurophysiologie de la douleur, les traitements non pharmacologiques et la manière de distinguer l'expression de la douleur des autres comportements. CONCLUSION : La présente étude a démontré que malgré une moyenne de plus de dix ans d'expérience dans les ÉSLD, les DdS ont des besoins de formation importants en matière de prise en charge de la douleur, particulièrement l'évaluation de la douleur. Ces résultats contribueront à la mise sur pied d'un programme de formation complet sur la prise en charge de la douleur à l'intention des DdS des ÉSLD.

(5). Older persons are also at a higher risk of neuropathic pain, including postherpetic neuralgia, for which advanced age is the main risk factor (11). Reduced pain modulation capacity and deficient descending inhibition have also been discerned in older persons (12). The frequent presence of comorbidities in older persons residing in LTCF increases the risk of suffering from chronic pain (13). However, such intrinsic factors play a relatively minor role; poor pain assessment and management may have a much more negative impact (14).

Several factors may contribute to inadequate pain management in older adults. First, it is well known that they tend to under-report pain, either due to false beliefs, misconceptions or misinterpretation of physical symptoms (15). Second, it has been determined that

\footnotetext{
${ }^{1}$ School of Rehabilitation, Université de Sherbrooke; ${ }^{2}$ Centre de recherche Clinique Etienne-LeBel, Centre hospitalier universitaire de Sherbrooke;

${ }^{3}$ Research Centre on Aging, Institut universitaire de gériatrie de Sherbrooke, Sherbrooke; ${ }^{4}$ Institut universitaire de gériatrie de Montréal,

Université de Montréal; ${ }^{5}$ Division of Geriatric Medicine and Alan-Edwards Centre for Research on Pain, McGill University; ${ }^{6}$ Centre de pédagogie appliquée aux sciences de la santé, Faculté de médecine, Université de Montréal, Montreal; ${ }^{7}$ Hôpital Ste-Anne, Sainte-Anne-deBellevue; ${ }^{8}$ Faculté de pharmacie, Université de Montréal, Montreal; ${ }^{9}$ Sanofi-Aventis Endowment Chair in Ambulatory Pharmaceutical Care, Faculté de pharmacie and Centre de santé et de services sociaux de Laval; ${ }^{10} E$ quipe de recherche en soins de première ligne, Centre de santé et de services sociaux de Laval, Laval; ${ }^{11}$ Centre de recherche, Centre hospitalier de l'Université de Montréal; ${ }^{12}$ Department of Anesthesiology, Faculté de médecine, Université de Montréal, Montreal, Quebec

Correspondence: Dr Manon Choinière, Centre de recherche, Centre hospitalier de l'Université de Montréal - Hôtel-Dieu, Vimont Pavilion, 3840 Saint Urbain Street, Room 3-227, Montreal, Quebec H2W 1T8. Telephone 514-890-8000 ext 14082,

fax 514-412-7027, e-mail manon.choiniere@umontreal.ca
} 
approximately $60 \%$ of older persons in pain do not ask for analgesics (16). Finally, pain among older persons is often neglected (ie, not periodically assessed) or even not assessed at all (17-19). Pain evaluation by health care providers (HCPs) is difficult and, hence, inadequate in patients with cognitive deficits (dementia) or communication problems, which are common in LTCF (20). Even though there are several validated scales for the assessment of pain in persons who cannot communicate, a lack of knowledge regarding proper pain measurement techniques prevents adequate evaluation and, subsequently, proper management of pain in this population (21).

Several studies have shown that pain is undertreated in LTCF (22), especially in patients with dementia, who receive less analgesic medications than those without dementia (18). In addition to being undertreated, pain is, unfortunately, sometimes managed inadequately. For example, studies have disclosed that older adults with dementia are prescribed more psychotropic medications than analgesic medications for their pain $(23,24)$.

Other factors, mostly related to HCPs, can also explain poor pain management in LTCF. Many HCPs have false beliefs and misconceptions regarding pain (25-28), including that it is normal for people to have pain when they get older, that older adults perceive less pain than younger adults (15), that opioids lead to dependence (29), that older adults are complainers, fear of inducing respiratory depression or fear of giving the last (ie, lethal) dose of opioids $(30,31)$. These false beliefs have a major impact on pain management, resulting in underuse or no use of analgesics in LTCF (22). There is also a general lack of knowledge regarding pharmacological treatments and fallacies about analgesics (29), which can evoke reluctance on the part of HCPs to provide proper pharmacological treatments (19).

Given that pain in patients living in LTCF is very common, underdiagnosed and often inadequately treated, there are several good reasons to implement strategies to improve pain management in LTCF (32). This is especially true for very old patients or those with dementia (33-35). In fact, improving pain management strategies in LTCF has become a key priority for many organizations, including the Canadian Council on Health Services Accreditation, which recently integrated a component on pain management into its norms to improve clinical practices. Major organizations such as the International Association for the Study of Pain (36) and the American Geriatrics Society (37) have also identified improvement in pain management as a key priority.

Part of the solution to improving pain management in LTCF would be to deploy interdisciplinary professional educational programs for HCPs $(25,38,39)$. However, to be successful, such educational programs must be developed in close collaboration with HCPs (40). Although it is quite clear that HCPs need better pain assessment and management strategies, the specific content that would help improve their skills remains unknown. Obtaining this information is crucial, as educational programs solely aiming to improve pain assessment have not demonstrated convincing results so far (41).

Consequently, the present study is the first step in a vast knowledge transfer research program aimed at improving pain management in older individuals. In this context, its objective is to identify and prioritize the educational needs specifically perceived by each category of HCPs working in LTCF with regard to pain management.

\section{METHODS}

\section{Setting and participants}

A convenience sample of HCPs was recruited from three LTCF. These LTCF were chosen because they had an interest in being involved in the pain knowledge transfer research program. One of these facilities was university affiliated and had more than 700 beds. The two others were not university affiliated and were located in urban and suburban areas of the province of Quebec. HCPs, which included physicians, pharmacists, physical and occupational therapists and nurses, were conveniently enrolled via managers in each facility. Orderlies also participated in the present study because their duties involve patient care-related activities in the province of Quebec. The project was approved by the Ethics Review Board of the Research Centre on Aging of the Institut universitaire de gériatrie de Sherbrooke (IUGS).

\section{Design}

A qualitative research design using a nominal group technique (NGT) $(42,43)$ was chosen to meet the objective of the present study. The NGT is a process that facilitates effective group decision-making, generates a large number of ideas, minimizes researcher bias and ensures even participation from all group members (43). The purpose is to generate ideas about a question or an issue, which can then be prioritized. After proper introduction and explanations, stages of the NGT involve: silent generation of ideas; sharing ideas; clarification of ideas; and prioritizing ideas (43).

\section{Procedures}

After written informed consent was obtained from all participants, they were invited to fill out a short questionnaire for the collection of various demographic data and information about their work experience and level of education. Four nominal groups were formed within each LTCF, with six to eight participants each, grouped according to discipline (physicians and pharmacists, physical therapists and occupational therapists, nurses and orderlies). Each nominal group was structured according to the guidelines described by Potter et al (43). Participants were asked to silently generate ideas on the following question: "What do you think should be the content of a training session, developed for you, on the management of chronic pain in older adults residing in long-term care facilities?" After 15 min of individual work, subjects were asked to share their ideas. A research assistant recorded each idea proposed by participants on a flip chart via a round-robin process. This was repeated until the ideas of all participants were exhausted. After this first step, the facilitator (YTL), who had clinical experience in pain management, clarified the ideas and classified similar items into themes or categories - no ideas were eliminated. At the end of the process, categories were labelled according to the nature of the ideas generated by the participants. Finally, after the clarification and classification of ideas, each participant was asked to prioritize the items by ranking them on a scale from 1 (least important) to 7 (most important).

\section{Data analysis}

As proposed by Potter et al (43), to identify group priorities, data were analyzed according to a quantitative approach. This was performed using the ranks assigned to each item by the four different categories of HCPs. Themes that received no vote (score of zero) were eliminated. This approach was chosen to clearly identify the top priorities in pain education.

Each item was then scored according to the sum of votes received. This score was divided by the number of participants within the group to obtain a weighted score, which took into account the fact that the number of participants per group varied. The weighted scores of the different groups were then averaged. Finally, each mean weighted score was multiplied by the number of times it was generated in each study site (weighting factor). For example, if the item pain assessment was generated by each group in the three sites, it was assigned a weighting factor of three. In contrast, if it was only generated in two out of the three sites, it was given a weighting factor of two. An example of this calculation method is outlined in Table 1.

\section{Participants}

\section{RESULTS}

Among the three LTCF, a total of 72 individuals agreed to participate in the nominal groups: nine physicians, three pharmacists, 15 rehabilitation professionals (six physical therapists and nine occupational therapists), 24 nurses and 21 orderlies. The age of the participants ranged from 22 to 57 years (mean \pm SD age $41.4 \pm 8.8$ years), and the majority were female (66/72), except in the physicians/pharmacists category. Participants had a median of 10 years of practice in LTCF (range six months to 32 years). When they were asked to estimate the 


\begin{tabular}{|c|c|c|c|c|c|c|}
\hline \multicolumn{7}{|c|}{ Health care provider category: Nursing } \\
\hline \multirow[b]{2}{*}{ Item } & \multicolumn{3}{|c|}{$\begin{array}{c}\text { Weighted score } \\
\text { (total score/number of participants in NGT) }\end{array}$} & \multirow{2}{*}{$\begin{array}{c}\text { Mean of weighted } \\
\text { scores } \\
\text { (mean of three sites) }\end{array}$} & \multirow{2}{*}{$\begin{array}{c}\text { Weighting factor } \\
\text { (number of sites where } \\
\text { item was nominated) }\end{array}$} & \multirow{2}{*}{$\begin{array}{c}\text { Final score } \\
\text { (mean } \times \text { weighting } \\
\text { factor) }\end{array}$} \\
\hline & Site 1 & Site 2 & Site 3 & & & \\
\hline Pain assessment & 5.62 & 4.37 & 5.02 & 5.02 & 3 & 15.07 \\
\hline Signs and symptoms of pain & 4.62 & - & 4.85 & 4.74 & 2 & 9.48 \\
\hline
\end{tabular}

NGT Nominal group technique

\section{TABLE 2}

Participants' characteristics

\begin{tabular}{|c|c|c|c|c|c|c|}
\hline & \multirow[b]{2}{*}{$\mathbf{n}$} & \multirow[b]{2}{*}{ Female sex, \% } & \multirow{2}{*}{$\begin{array}{l}\text { Age, years, } \\
\text { mean } \pm S D\end{array}$} & \multirow{2}{*}{$\begin{array}{c}\text { Years of } \\
\text { practice in LTCF }\end{array}$} & \multicolumn{2}{|c|}{ Estimated hours of continuing education } \\
\hline & & & & & Geriatric medicine & Pain management \\
\hline All participants & 72 & 92 & $41.4 \pm 8.89 .3$ & $10(0.5-32)$ & $22(21-48)$ & $0(0-100)$ \\
\hline Physicians and pharmacists & 12 & 7 & $40.1 \pm 9.3$ & $9.5(0.5-30)$ & $33(10-135)$ & $13.5(0.5-30)$ \\
\hline Rehabilitation professionals & 15 & 100 & $38.2 \pm 9.0$ & $5(2-25)$ & $35(14-190)$ & $0(0-5)$ \\
\hline Nurses & 24 & 100 & $43.1 \pm 9.9$ & $15(0.25-30)$ & $21(7-50)$ & $0(0-30)$ \\
\hline Orderlies & 21 & 76 & $42.9 \pm 8.5$ & $10(0.25-32)$ & $20(0-150)$ & $0(0-2)$ \\
\hline
\end{tabular}

Data presented as median and range (minimum - maximum) unless otherwise indicated. LTCF Long-term care facilities

number of hours of continuing education $(\mathrm{CE})$ they received in the past three years, the different groups reported a total ranging from $21 \mathrm{~h}$ to $190 \mathrm{~h}$ in geriatric medicine, with less than $10 \%$ of the total number of CE hours being devoted to pain management. Detailed information on each category of HCPs is summarized in Table 2.

Educational needs in chronic pain management in older patients The sample of participants generated ideas which resulted in 40 different categories. Each category reflects the needs regarding pain management they believed were important to be addressed in an educational seminar. Of these 40 topics, six were common to at least three of the four groups of HCPs and included pain assessment, pharmacological treatment of pain, nonpharmacological modalities in pain management, pain neurophysiology, clinical signs of pain as opposed to other sensations/ emotions and best communication strategies. Table 3 presents all identified needs prioritized for each category of HCPs. Although some topics are self-explanatory (ie, what are the biopsychosocial impacts of pain?), some of them encompass many ideas. More detailed information was reported on six common topics expressed by at least three of the four HCP groups.

\section{Pain assessment}

Regardless of the discipline, pain assessment was the top-rated topic among all educational needs and consequently obtained the highest weighting factor, which ranged from 13.2 to 18.9. All HCPs believed that they had very limited knowledge about this important component of pain management. They wanted to become familiar with pain assessment tools and learn how to use pain assessment tools designed for residents who are unable to communicate. Although they provide care for many patients with dementia on a daily basis, they admitted their lack of knowledge on the topic of pain assessment, in terms of both the instruments and the procedures to be used with this particular clientele. Furthermore, they wished to be better informed about the factors/components that characterize and differentiate acute versus chronic pain.

\section{Pharmacological management of pain}

The pharmacological management of pain was also very highly rated by all HCPs. The highest weighting factor (14.0) was in nurses and the lowest (2.3) in orderlies. However, the specific educational needs in this domain expressed by nurses, rehabilitation professionals and orderlies differed from those identified by physicians and pharmacists. The former group expressed that they required more education/information about the basic mechanisms of action of different types of analgesics (eg, opioids, nonopioids), their characteristics (eg, differences between codeine and morphine), and their respective properties in terms of onset and duration of action. For example, participants wished to know how long a given medication should be administered before a therapeutic procedure (eg, a dressing change or physiotherapy session). In contrast, physicians and pharmacists had very specific needs and requested more information about drug interactions, management of adverse effects, best treatment strategies for neuropathic pain (eg, coanalgesics, topical analgesics), progression and substitution of pharmacological agents (ie, indications and principles of prescription).

\section{Nonpharmacological modalities in pain management}

While nonpharmacological approaches were, not surprisingly, rated highly by rehabilitation professionals, they were also prioritized by all other HCPs, as revealed by weighting factors ranging from 4.6 (physicians) to 10.0 (rehabilitation professionals). Participants complained about their lack of knowledge of ways to alleviate pain without medication, including use of transcutaneous nerve stimulation, positioning, relaxation, breathing techniques and exercises. All HCPs wanted to know the effectiveness of such nonpharmacological approaches in reducing acute and chronic pain.

\section{Pain neurophysiology}

Another common point of interest among all HCPs was pain neurophysiology, in which the weighting factor ranged from 3.9 to 13.3. Physicians/pharmacists, rehabilitation professionals and nurses manifested a strong interest towards greater comprehension of neurophysiological mechanisms of pain. For their part, orderlies believed they had poor knowledge regarding the processes involved in the development of chronic pain in older adults and its relationship with the different painful pathologies encountered among the aged.

\section{Clinical signs of pain}

Although this topic could easily have been included under 'pain assessment', HCPs systematically reported it as an independent item. Therefore, it was classified as a single category to better reflect HCP's expressed needs. All HCPs believed they did not know how to recognize the specific clinical signs and symptoms of pain, especially in patients unable to communicate or patients with dementia, and needed more information on how to recognize specific pain behaviours. For example, they wanted to know which facial expressions usually indicate the presence of pain and if patients with dementia show reduced or increased expressions of pain. They also wanted to know how to determine when nonspecific pain behaviours, such as crying or agitation, were related to pain or to another problem (eg, depression, loneliness). Finally, they wanted to know if vital signs were good indicators of the presence of pain. Physicians and pharmacists had the lowest weighting factor (1.5) while rehabilitation professionals had the highest (11.0). 
TABLE 3

Educational needs and weighted scores identified and prioritized by health care providers working in three long-term care facilities

\begin{tabular}{|c|c|c|c|c|}
\hline & Physicians and pharmacists & Rehabilitation professionals & Nurses & Orderlies \\
\hline 1 & Pain assessment (13.2) & Pain assessment (18.9) & Pain assessment (15.1) & Pain assessment (15.9) \\
\hline 2 & $\begin{array}{l}\text { Pharmacological management of } \\
\text { pain (8.4) }\end{array}$ & Clinical signs of pain (11.0) & $\begin{array}{l}\text { Pharmacological management of } \\
\text { pain (14.0) }\end{array}$ & $\begin{array}{l}\text { Proper positioning and mobilizing } \\
\text { techniques (13.0) }\end{array}$ \\
\hline 3 & $\begin{array}{l}\text { Accumulation of pharmacological } \\
\text { agents: when to progress or } \\
\text { substitute (5.3) }\end{array}$ & $\begin{array}{l}\text { Nonpharmacological modalities in } \\
\text { pain management }(10.0)\end{array}$ & Pain neurophysiology (13.3) & $\begin{array}{l}\text { Nonpharmacological modalities in } \\
\text { pain management }(9.3)\end{array}$ \\
\hline 4 & $\begin{array}{l}\text { Nonpharmacological modalities in } \\
\text { pain management }(4.6)\end{array}$ & Pain neurophysiology (8.7) & Clinical signs of pain (9.5) & $\begin{array}{l}\text { Painful pathologies in the elderly } \\
\text { (7.6) }\end{array}$ \\
\hline 5 & Pain neurophysiology (3.9) & $\begin{array}{l}\text { Specific roles of HCPs in pain } \\
\text { management strategies (4.6) }\end{array}$ & $\begin{array}{l}\text { Pain management for palliative care } \\
\text { patients (8.1) }\end{array}$ & $\begin{array}{l}\text { When to stop active treatment and } \\
\text { start comfort care }(5.9)\end{array}$ \\
\hline 6 & $\begin{array}{l}\text { Pharmacological treatments in } \\
\text { relation to comorbidities (3.6) }\end{array}$ & $\begin{array}{l}\text { Pharmacological management of } \\
\text { pain }(4.4)\end{array}$ & $\begin{array}{l}\text { Nonpharmacological modalities in } \\
\text { pain management (7.1) }\end{array}$ & How to reassure the patient (4.9) \\
\hline 7 & $\begin{array}{l}\text { Managing side effects of } \\
\text { pharmacotherapy (2.8) }\end{array}$ & $\begin{array}{l}\text { When to stop active treatment and } \\
\text { start comfort care (3.7) }\end{array}$ & Biopsychosocial impacts of pain (2.5) & $\begin{array}{l}\text { Best communication strategies } \\
\text { between HCPs }(3.7)\end{array}$ \\
\hline 8 & $\begin{array}{l}\text { Specific roles of HCPs in pain } \\
\text { management strategies }(2.6)\end{array}$ & $\begin{array}{l}\text { When to pay particular attention to } \\
\text { clinical signs of pain (3.5) }\end{array}$ & Education of family members (1.9) & $\begin{array}{l}\text { Do's and don'ts in regard to patients' } \\
\text { medical history (3.3) }\end{array}$ \\
\hline 9 & Clinical signs of pain (1.5) & $\begin{array}{l}\text { Pain management } \\
\text { algorithm (3.3) }\end{array}$ & $\begin{array}{l}\text { How to mobilize patients without } \\
\text { enhancing pain }(1.0)\end{array}$ & $\begin{array}{l}\text { How to distinguish acute versus } \\
\text { chronic pain (3.0) }\end{array}$ \\
\hline 10 & Management of episodic pain (1.3) & $\begin{array}{l}\text { Effectiveness of pain management } \\
\text { strategies (3.1) }\end{array}$ & Long-term assessment of pain (0.6) & Psychosocial impacts of pain (2.4) \\
\hline 11 & $\begin{array}{l}\text { Establishing the best analgesic dose } \\
\text { without inducing functional } \\
\text { impairments (0.6) }\end{array}$ & $\begin{array}{l}\text { Consequences and impact of chronic } \\
\text { pain }(2.7)\end{array}$ & $\begin{array}{l}\text { Painful pathologies in the elderly } \\
(0.3)\end{array}$ & $\begin{array}{l}\text { Pharmacological management of } \\
\text { pain }(2.3)\end{array}$ \\
\hline 12 & Invasive treatment modalities $(0.57)$ & $\begin{array}{l}\text { Best communication strategies } \\
\text { between HCPs (2.2) }\end{array}$ & $\begin{array}{l}\text { How to identify dependence on } \\
\text { opioids }(0.25)\end{array}$ & $\begin{array}{l}\text { Why patients in pain are often } \\
\text { aggressive }(2.0)\end{array}$ \\
\hline 13 & Intra-articular injections (0.6) & $\begin{array}{l}\text { Active approaches to treat pain in the } \\
\text { elderly (1.9) }\end{array}$ & $\begin{array}{l}\text { Treatment of pain in demented } \\
\text { patients }(0.3)\end{array}$ & Cancer-related pain (1.1) \\
\hline 14 & $\begin{array}{l}\text { Functional impacts of pain in LTCF } \\
\text { residents }(0.3)\end{array}$ & $\begin{array}{l}\text { How pain and dementia interact and } \\
\text { affect mobility (1.5) }\end{array}$ & $\begin{array}{l}\text { Systematic monitoring of pain in old } \\
\text { persons }(0.1)\end{array}$ & Role of nutrition in pain $(0.9)$ \\
\hline \multirow[t]{2}{*}{15} & $\begin{array}{l}\text { Misbeliefs of HCPs and families } \\
\text { regarding the use of opioids }(0.1)\end{array}$ & $\begin{array}{l}\text { Pain management at the end of life } \\
(0.5)\end{array}$ & & \\
\hline & & Cancer-related pain $(0.4)$ & & \\
\hline
\end{tabular}

Numbers in parentheses represent the final score obtained for each item based on calculations described in the data analysis section. Specific items that were identified among the majority of health care provider categories are coded in shades of grey for easier identification. HCP Health care providers; LTCF Long-term care facilities

\section{Best communication strategies}

The best communication strategies regarding pain were also a topic of interest expressed by all HCPs except nurses. They wanted to know the specific roles of each discipline, how to optimize teamwork and how to communicate pain-related information from one discipline to another (eg, from orderlies to nurses). The weighting factor of this topic ranged from 2.6 to 4.6 .

\section{DISCUSSION}

The main goal of the present study was to identify and prioritize the educational needs of HCPs working in LTCF with regard to pain management for use in the development of a web-based educational intervention whose content meets the users' demands.

The results of the present study found that for all categories of HCP, the educational need for pain assessment (and especially in residents with communication impairments and/or dementia) was very highly ranked, suggesting that HPCs are poorly equipped in this area. These results are consistent with those obtained in previous quantitative studies, which ascertained that HCPs had poor pain assessment techniques, especially in residents with dementia $(17,39,44)$. To our knowledge, the present study was the first to adopt a qualitative approach to highlight specific learning needs in pain management by HCPs working in LTCF.

Pharmacological and nonpharmacological modalities to relieve pain as well as pain neurophysiology were also topics that were highly rated in terms of education needs. These results indicate that HCPs want to better understand the mechanisms causing pain in older persons and to have more options to better manage it. The specific needs identified for each HCP discipline are closely related to the nature of their role in pain management (26).

Another important topic among highly ranked needs dealt with communication issues within multidisciplinary teams. HCPs wanted to know the specific roles of each health care provider involved in patient care and the best strategies to effectively communicate painrelated information. This finding can be viewed as somewhat unforeseen. Even though our sample had several years of work experience in LTCF, they believed that they did not know how to effectively communicate pain-related information to other members of the multidisciplinary team.

Another interesting finding of the present study was related to the very limited number of hours of CE devoted to pain management. We observed that, despite the fact that HCPs working in LTCF are confronted by acute and chronic pain in their patients on a daily basis, they received very limited CE on this topic. In fact, except for physicians and pharmacists, all HCPs had less than $10 \%$ of their total CE hours dedicated to pain management. However, nurses and orderlies spend much more time with patients than physicians and pharmacists. These findings, which confirm the results of several other studies $(13,21,45)$, support the need to develop comprehensive educational programs in pain management. Furthermore, these findings are not 
only important for developing a CE curriculum, but also for pain curricula in undergraduate programs, such as medicine, pharmacy, rehabilitation and nursing.

The highly ranked items discussed above will define the major part of our educational program. With these top rated educational needs, we will build web-based learning seminars that will include modules on pain assessment, pain neurophysiology, nonpharmacological therapeutic options and pharmacological approaches for physicians and nonphysicians. The items within the top 10 not addressed within the webbased learning seminars will be addressed by group discussions that will be conducted on each ward during an in-person training session.

Although educational programs to improve pain management already exist (eg, www.geriatricpain.org, www.nhqualitycampaign.org), our webbased learning seminars will offer the advantage of being customized to the expressed needs of HCP working in LTCF, and will also integrate an interactive portion in which individual participants will have the chance to receive more detailed information relevant to their facility.

There are several strengths to the present study. As mentioned earlier, it is the first to use a qualitative design (NGT) to document the specific learning needs of HCPs working in LTCF. The NGT is a scientifically recognized method of assessing and facilitating the generation and prioritization of ideas in a clinical setting (43) and is known to have high internal validity (46). By recruiting HCPs directly involved in daily patient care in LTCF, we ensured that the expressed educational needs reflected challenges met in clinical practice. Finally, the fact that we had three groups of participants for each discipline enabled us to identify all important educational needs, as shown by a rapid achievement of a saturation of ideas, without any new ideas (needs) emerging after the second group of participants. This considerably increases the generalization of our findings.

There are also several limitations to the present study. The HCPs who chose to participate in the NGT were interested in the study topic, which created a certain selection bias. This was also true for LTCF selection, as they were selected on the basis of their interest in testing the educational program to be developed from the present research. However, interest in the topic is not necessarily a negative thing in the context of changing clinical practices, a process that is known to be extremely difficult (47). Based on adult learning principles, the development of a learning curriculum must involve the participation of actual players and be designed in accordance with the learner's needs and interests (48). Once the program has been created and proves to have a positive impact, it can be proposed to other HCPs who are more or less interested in the topic but who can now realize its utility and relevance. Another limitation comes from the fact that we only assessed the perceived needs of a convenience sample of HCPs working in LTCF rather than the actual knowledge deficits of the entire group; our educational program might be incomplete because there may be some theoretical needs that HCPs are not aware of. However, we will include the participation of content experts during the in-person training, and these experts will ensure that the actual theoretical needs will be addressed in addition to the perceived needs.

The results of the present study have some important clinical and educational implications. No other study previously established the needs of HCPs in LTCF with regard to pain education in the context of health care services in Quebec and Canada. The results obtained through the NGT will help define, prioritize and structure the basis of an educational program tailored to HCPs' perceived needs, and its main objective is to enhance pain management and alleviate the burden of pain in LTCF. The findings of the present study will be presented to a panel of Canadian pain experts (researchers and clinicians) to optimize the development and design of the web-based intervention and to identify the most appropriate methodologies to assess its efficacy and impact.

\section{Improvement of pain management strategies in LTCF}

Strategies implanted to improve pain assessment alone do not always culminate in better clinical outcomes such as reduced pain prevalence (41). The campaign 'Pain as the fifth vital sign', a strategy implanted to improve pain management, is a good example (49). Although educational interventions can certainly help, better health care policies established by decision makers are probably needed to achieve positive changes in clinical practices. As outlined by many authors $(38,50)$, policies that incorporate a quality improvement approach are needed, because they will provide the foundation for sustained success and help in transforming current pain management strategies in LTCF. Studies by Leone et al (51) and Keeney et al (47) have adopted such an approach, with promising results.

\section{CONCLUSION}

The present study is the first step in a vast knowledge transfer research program aimed at improving pain management in older persons (www.programmeaccord.org). The results uncovered common needs among all groups of HCPs, including pain assessment (which was ranked as the most relevant topic by all groups of HCPs), clinical signs of pain, pharmacological and nonpharmacological pain treatments, pain neurophysiology as well as communication strategies between each group of HCPs. These themes will define the major part of our educational program, because these necessarily reflect the perceived needs of HCPs working in LTCF. We hope that by addressing these specific needs we will optimize pain management, including improving pain assessment and treatment in LTCF and hopefully reducing the burden of pain in elderly persons residing in such institutions.

DISCLOSURES: The present study was funded by a Team Grant: Community Alliances for Health Research and Knowledge Exchange on Pain from the Canadian Institutes of Health Research, in partnership with AstraZeneca Inc (Grant No CAH - 86787) and by Pfizer Canada Inc. Lyne Lalonde has received research and educational grants from Amgem Canada Inc, AstraZeneca Canada Inc, Janssen-Ortho Inc, Léo-Pharma, Merck Frosst Canada Ltée, Purdue Pharma, Pfizer Canada Inc, and Sanofi Aventis. Manon Choinière has received research grants from Pfizer Canada Inc and AstraZeneca Inc. She also received consulting fees and speaking honoraria from Pfizer Canada Inc. Yannick Tousignant-Laflamme was supported by a postdoctoral fellowship from the Quebec Rehabilitation Research Network of the Fonds de la recherche en santé du Québec. He is presently a supported member of the Centre de recherche Clinique Etienne-LeBel, Centre hospitalier universitaire de Sherbrooke (CHUS). The authors have no conflicts of interest.

ACKNOWLEDGMENTS: The authors thank Marie-Claude Girard and Valérie Tremblay-Boudreault for their help in the NGT process. Thanks are also due to Mr Ovid M Da Silva for manuscript review and editing.

\section{REFERENCES}

1. Ramage-Morin PL. Chronic pain in Canadian seniors. Health Reports Statistic Canada 2008;19:37-52.

2. Helme RD, Gibson SJ. The epidemiology of pain in elderly people. Clin Geriatr Med 2001;17:417-31.

3. Achterberg WP, Gambassi G, Finne-Soveri H, et al. Pain in European long-term care facilities: Cross-national study in Finland, Italy and The Netherlands. Pain 2010;148:70-4.

4. Barkin RL, Barkin SJ, Barkin DS. Perception, assessment, treatment, and management of pain in the elderly. Clin Geriatr Med 2005;21:465-90.

5. Proctor WR, Hirdes JP. Pain and cognitive status among nursing home residents in Canada. Pain Res Manag 2001;6:119-25.

6. Maxwell CJ, Dalby DM, Slater M, et al. The prevalence and management of current daily pain among older home care clients. Pain 2008;138:208-16.

7. Torvik K, Kaasa S, Kirkevold O, Rustoen T. Pain and quality of life among residents of Norwegian nursing homes. Pain Manag Nurs 2010;11:35-44

8. Husebo BS, Strand LI, Moe-Nilssen R, Husebo SB, Ljunggren AE. Pain in older persons with severe dementia. Psychometric properties of the Mobilization-Observation-Behaviour-Intensity-Dementia (MOBID-2) Pain Scale in a clinical setting. Scand J Caring Sci 2010;24:380-91. 
9. Baan MA, Mesa AA, der Steen AL, van der Rijt CC. Survey on the prevalence of pain in Dutch district nursing care. J Palliat Med 2011;14:696-9

10. Landi F, Onder G, Cesari M, et al. Pain management in frail, community-living elderly patients. Arch Intern Med 2001;161:2721-4

11. Drolet M, Brisson M, Schmader K, et al. Predictors of postherpetic neuralgia among patients with herpes zoster: A prospective study. J Pain 2010;11:1211-21.

12. Edwards RR, Fillingim RB, Ness TJ. Age-related differences in endogenous pain modulation: A comparison of diffuse noxious inhibitory controls in healthy older and younger adults. Pain 2003;101:155-65.

13. Fox PL, Raina P, Jadad AR. Prevalence and treatment of pain in older adults in nursing homes and other long-term care institutions: A systematic review. CMAJ 1999;160:329-33.

14. Herr K, Titler MG, Schilling ML, et al. Evidence-based assessment of acute pain in older adults: Current nursing practices and perceived barriers. Clin J Pain 2004:20:331-40.

15. Gagliese L, Melzack R. Chronic pain in elderly people. Pain 1997;70:3-14.

16. Jones K. Effective pain management: Lessons from a nursing home research study. J Healthc Qual 2006;28:41-7.

17. Zwakhalen SM, Hamers JP, Peijnenburg RH, Berger MP. Nursing staff knowledge and beliefs about pain in elderly nursing home residents with dementia. Pain Res Manag 2007;12:177-84.

18. Pickering G, Jourdan D, Dubray C. Acute versus chronic pain treatment in Alzheimer's disease. Eur J Pain 2006;10:379-84.

19. Tarzian AJ, Hoffmann DE. Barriers to managing pain in the nursing home: Findings from a statewide survey. J Am Med Dir Assoc 2005;6:S13-9.

20. Zwakhalen SM, Hamers JP, Abu-Saad HH, Berger MP. Pain in elderly people with severe dementia: A systematic review of behavioural pain assessment tools. BMC Geriatr 2006;6:3.

21. Herr K. Chronic pain: Challenges and assessment strategies. J Gerontol Nurs 2002;28:20,7; quiz 54-5.

22. Won AB, Lapane KL, Vallow S, Schein J, Morris JN, Lipsitz LA. Persistent nonmalignant pain and analgesic prescribing patterns in elderly nursing home residents. J Am Geriatr Soc 2004;52:867-74.

23. Balfour JE, O'Rourke N. Older adults with Alzheimer disease, comorbid arthritis and prescription of psychotropic medications. Pain Res Manag 2003;8:198-204.

24. Hutt E, Pepper GA, Vojir C, Fink R, Jones KR. Assessing the appropriateness of pain medication prescribing practices in nursing homes. J Am Geriatr Soc 2006;54:231-9.

25. Gibson SJ. Older people's pain. Pain: Clinical updates 2006;14:1-4.

26. Herr K. Pain in the older adult: An imperative across all health care settings. Pain Manag Nurs 2010;11:S1-10.

27. Bergh I, Sjostrom B. A comparative study of nurses' and elderly patients' ratings of pain and pain tolerance. J Gerontol Nurs 1999;25:30-6.

28. Bjoro K, Herr K. Assessment of pain in the nonverbal or cognitively impaired older adult. Clin Geriatr Med 2008;24:237-62.

29. Auret K, Schug SA. Underutilisation of opioids in elderly patients with chronic pain: Approaches to correcting the problem. Drugs Aging 2005;22:641-54.

30. Parke B. Gerontological nurses' ways of knowing. Realizing the presence of pain in cognitively impaired older adults. J Gerontol Nurs 1998;24:21-8.
31. McCaffery M, Ferrell BR. Opioids and pain management: What do nurses know? Nursing 1999;29:48-52.

32. Hicks TJ. Ethical implications of pain management in a nursing home: A discussion. Nurs Ethics 2000;7:392-8.

33. Ferrell BA, Ferrell BR, Rivera L. Pain in cognitively impaired nursing home patients. J Pain Symptom Manage 1995;10:591-8.

34. Ferrell BA. The management of pain in long-term care. Clin J Pain 2004:20:240-3.

35. Horgas AL, Tsai PF. Analgesic drug prescription and use in cognitively impaired nursing home residents. Nurs Res 1998;47:235-42.

36. Gibson SJ. IASP global year against pain in older persons: Highlighting the current status and future perspectives in geriatric pain. Expert Rev Neurother 2007;7:627-35.

37. AGS Panel on Persistent Pain in Older Persons. The management of persistent pain in older persons. J Am Geriatr Soc 2002;50:S205-24.

38. Hadjistavropoulos T, Marchildon GP, Fine PG, et al. Transforming long-term care pain management in North America: The policyclinical interface. Pain Med 2009;10:506-20.

39. Allcock N, McGarry J, Elkan R. Management of pain in older people within the nursing home: A preliminary study. Health Soc Care Community 2002;10:464-71.

40. Griscti $\mathrm{O}$, Jacono J. Effectiveness of continuing education programmes in nursing: Literature review. J Adv Nurs 2006;55:449-56.

41. Hadjistavropoulos T, MacNab YC, Lints-Martindale A, Martin R, Hadjistavropoulos H. Does routine pain assessment result in better care? Pain Res Manag 2009;14:211-6.

42. Dewar A, White M, Posade ST, Dillon W. Using nominal group technique to assess chronic pain, patients' perceived challenges and needs in a community health region. Health Expect 2003;6:44-52.

43. Potter M, Gordon S, Hamer P. The nominal group technique: A useful consensus methodology in physiotherapy research. NZ J Physiother 2004;32:126-30.

44. Herr K. Chronic pain in the older patient: Management strategies. 2. J Gerontol Nurs 2002;28:28-34; quiz 54-5.

45. Zwakhalen SM, Koopmans RT, Geels PJ, Berger MP, Hamers JP. The prevalence of pain in nursing home residents with dementia measured using an observational pain scale. Eur J Pain 2009;13:89-93.

46. Jones J, Hunter D. Consensus methods for medical and health services research. BMJ 1995;311:376-80.

47. Keeney CE, Scharfenberger JA, O’Brien JG, Looney S, Pfeifer MP, Hermann CP. Initiating and sustaining a standardized pain management program in long-term care facilities. J Am Med Dir Assoc 2008;9:347-53.

48. Sparling LA. Enhancing the learning in self-directed learning modules. J Nurses Staff Dev 2001;17:199-205.

49. Mularski RA, White-Chu F, Overbay D, Miller L, Asch SM, Ganzini L. Measuring pain as the 5th vital sign does not improve quality of pain management. J Gen Intern Med 2006;21:607-12.

50. Weissman DE, Griffie J, Muchka S, Matson S. Improving pain management in long-term care facilities. J Palliat Med 2001;4:567-73.

51. Leone AF, Standoli F, Hirth V. Implementing a pain management program in a long-term care facility using a quality improvement approach. J Am Med Dir Assoc 2009;10:67-73. 


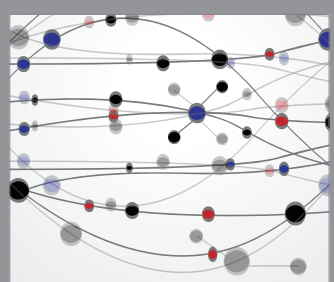

The Scientific World Journal
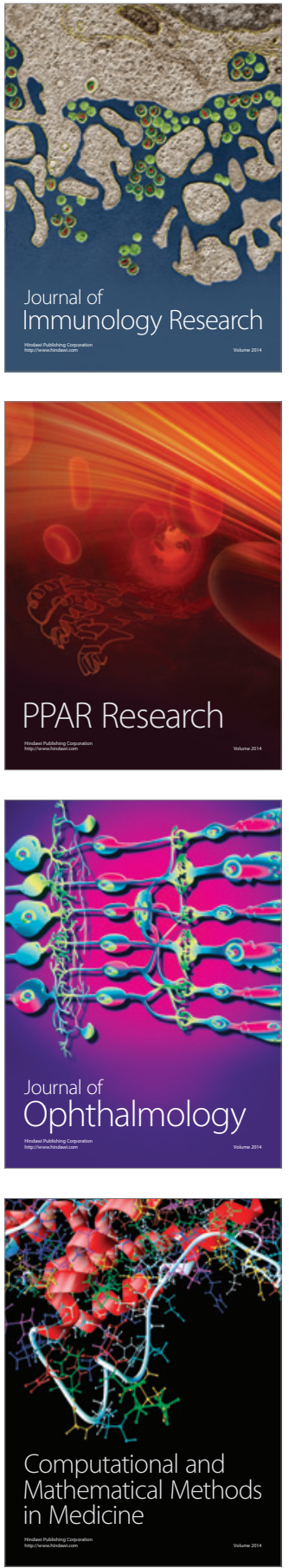

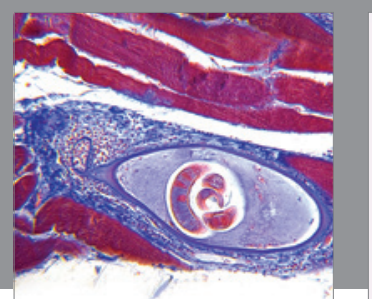

Gastroenterology Research and Practice

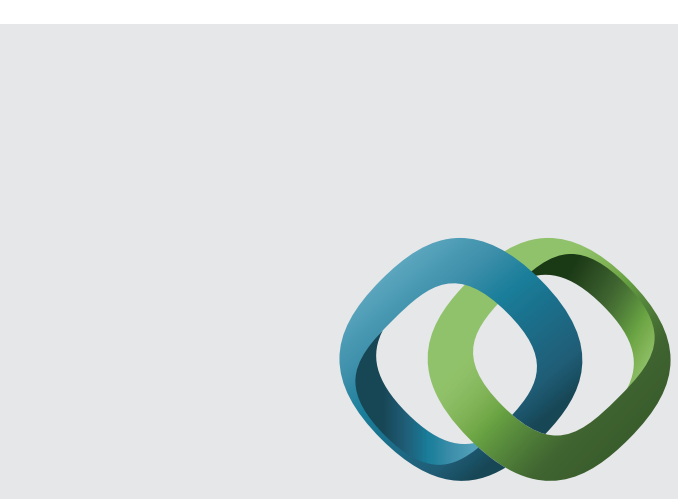

\section{Hindawi}

Submit your manuscripts at

http://www.hindawi.com
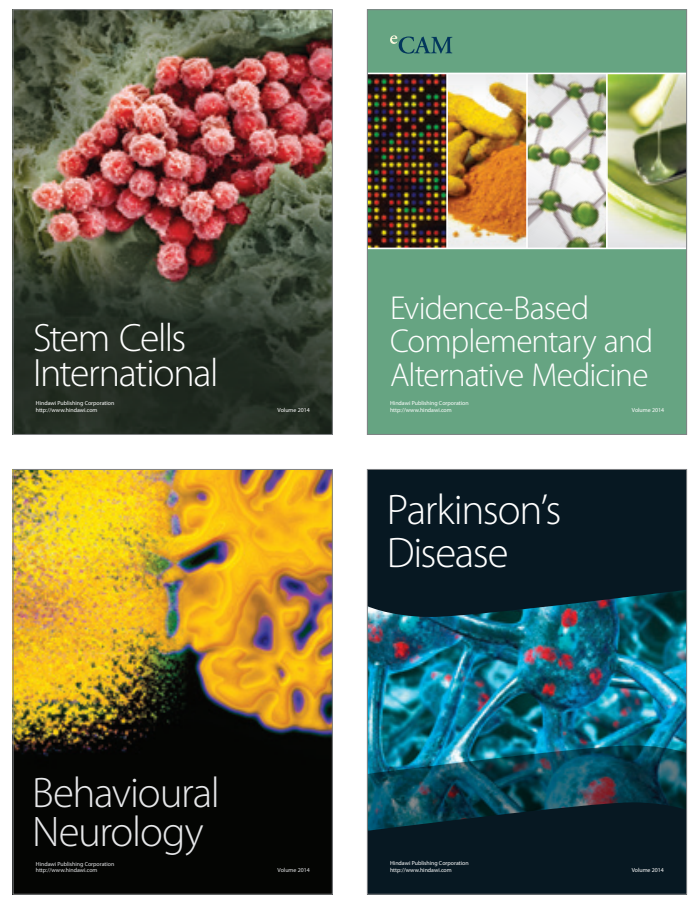
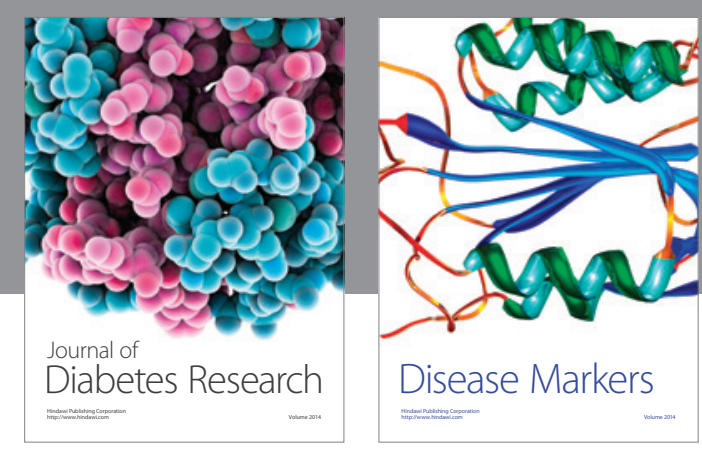

Disease Markers
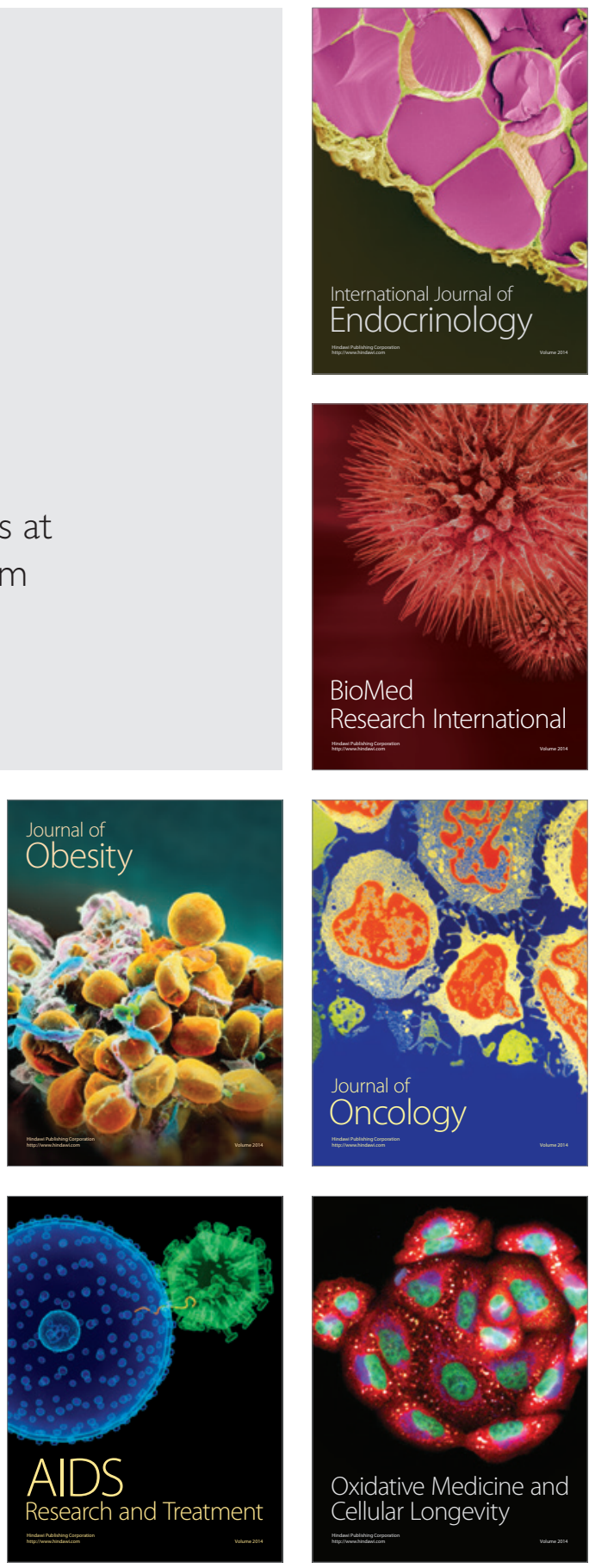